\title{
LoRaWAN Technology in Irrigation Channels in Batu Indonesia
}

\author{
Puput Dani Prasetyo Adi ${ }^{1}$, Akio Kitagawa ${ }^{2}$, Dwi Arman Prasetya ${ }^{3}$, Rahman Arifuddin ${ }^{4}$, Stanislaus Yoseph ${ }^{5}$ \\ 1,3,4,5 Department of Electrical Engineering, University of Merdeka Malang, Indonesia \\ ${ }^{2}$ Micro Electronics Research Laboratory, Kanazawa University, Japan
}

\begin{tabular}{|c|c|}
\hline ARTICLE INFO & ABSTRACT \\
\hline Article history: & Currently, agricultural technology or Farming development is increasingly \\
\hline $\begin{array}{l}\text { Received November 17, } 2021 \\
\text { Revised January } 15,2022\end{array}$ & $\begin{array}{l}\text { sophisticated by applying LoRaWAN-based IoT technology, ignoring quality } \\
\text { agricultural products. LoRaWAN used in this research uses Long-Range }\end{array}$ \\
\hline Accepted February 01, 2022 & $\begin{array}{l}\text { Frequency } 915 \mathrm{MHz} \text { and } 920 \mathrm{MHz} \text {. The case study in this research is a case } \\
\text { of river water quality that enters agricultural land or irrigation in Temas, Batu }\end{array}$ \\
\hline Keywords: & $\begin{array}{l}\text { City, where the river water has been contaminated by household waste. The } \\
\text { prototype installed on this farm uses an Arduino and Dragino LoRa } 915 \mathrm{MHz}\end{array}$ \\
\hline $\begin{array}{l}\text { LoRaWAN; } \\
\text { Irrigation; } \\
\text { Farming; } \\
\text { Monitoring; } \\
\text { Realtime }\end{array}$ & $\begin{array}{l}\text { microcontroller as transceivers and input and output devices consisting of } \\
\text { ultrasonic sensors and water } \mathrm{pH} \text { sensors, and outputs such as Solenoid valves } \\
\text { mounted on tub one and tub } 2 \text {. In contrast, tub } 3 \text { is a unique tub for distributing } \\
\text { water to agricultural land with normal water } \mathrm{pH} \text { quality. In this research, real- } \\
\text { time monitoring, especially on the conditions of water turbidity, water } \mathrm{pH} \text {, } \\
\text { and water level. }\end{array}$ \\
\hline
\end{tabular}

This work is licensed under a Creative Commons Attribution-Share Alike 4.0

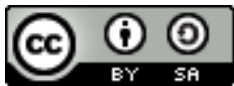

Corresponding Author:

Puput Dani Prasetyo Adi, Department of Electrical Engineering, University of Merdeka Malang, Terusan Raya Dieng Street Nu.62-64, Klojen, Sukun, Malang City, East Java 65146, Indonesia

Email: puput.danny@unmer.ac.id

\section{INTRODUCTION}

Modern farming works not only on agricultural land with large areas such as rice fields or gardens but also on hydroponics type crops or small land farming with the help of water. In this study, two things become the focus of research or research, i.e., regulating the $\mathrm{pH}$ of water in agricultural irrigation channels and plants with a hydroponics pattern. Both will be discussed in this research. In the two types of agriculture above, both use water $\mathrm{pH}$ control, so water $\mathrm{pH}$ will be a topic that needs to be discussed in detail in this research. Normal water $\mathrm{pH}$ is 6.5-7.5, equal to the soil $\mathrm{pH}$ value. There are two types of water $\mathrm{pH}$, namely alkaline $\mathrm{pH}(>7.5)$ and acidic $\mathrm{pH}(<6.5)$. Moreover, this water $\mathrm{pH}$ value is entered into a computer program on the Arduino IDE Microcontroller, which is combined into one of the output determinants, e.g., the Solenoid Valve.

Furthermore, the agricultural land used is in the Batu area, East Java, located in a mountainous area, with a large intake of mountain water and springs that are clear and free from pollution, unlike urban areas. However, the $\mathrm{pH}$ of the water is still influenced by the flow of water before entering the agricultural area, namely the flow of river water that passes through the residential areas there. The Solenoid valve is used as a water regulator that can flow or close at the output. Here, the Solenoid valve is one of the output devices from the microcontroller with $\mathrm{pH}$ water and ultrasonic sensor input.

Moreover, all outputs that are displayed in real-time must pass through an Application Programming Interface (API) process found on the Application Server. Furthermore, the Application Server used uses the Thingspeak App from MathWorks.inc., and TTN (The Things Network), devices that can connect to IoT, for example, are Arduino Wi-Fi Shield, ESP32, ESP 8266, Bluetooth Low Energy, ZigBee Internet Gateway, LoRaWAN Modules, LoRa End node as a transceiver, and other IoT devices [1][2][3][4][5][6].

The contribution of this research is to assist farmers in producing higher quality outputs or harvests, such as the size of shallots, garlic, and leaf width of pakcoy, which affect the quality of sales, consumers, and higher prices. This can be realized from watering arrangements monitoring the quality of water $\mathrm{pH}$, soil $\mathrm{pH}$, and soil moisture which are monitored automatically using devices based on microcontrollers and the Internet of Things 
(IoT). The next contribution is to provide LoRaWAN analysis results that are specific to Agricultural. Accordingly, the ability of LoRaWAN as a transceiver is low Bit Rate (bps) with a long-range, with an obstacle $(3 \mathrm{~km})$ and Line of Sight $(\mathrm{LoS})$ reaching $15 \mathrm{~km}$ to get LoRa Gateway and this analysis is used by Lora analyzer to measure LoRa signal strength more specifically.

\section{METHOD}

\subsection{LoRa Architecture Concept and Method}

Fig. 1 is Communication between LoRa End Node LoRa Gateway [7], MQTT Server, and an IoT-based LoRa [8][9][10][11][12][13][14]. The device in question is the End node or Easy LoRa Node, which then communicates with the LoRa Gateway using a specific LoRa Radio Frequency (RF) module [15][16][17][18][19], e.g., $915 \mathrm{MHz}$ or $920 \mathrm{MHz}$ which the author has tested. While the Gateway used is the Dragino LG01-P Gateway. The function of LG01-P is to receive all data sent by the LoRa End-node [18], which will be continued to the Network Server or users using 3G/4G/Ethernet/Wi-Fi included in the Network Server Application Server as a viewer of Real-time data. Accordingly, LoRa sends a minimal Bit Rate, which is $125 \mathrm{kbps}$. It is not possible to send photos or videos.

Moreover, no less important is the MQTT (Message Queuing Telemetry Transport) Server, which is a simple method of transmitting data when communicating with IoT devices and Application Servers or Internet Servers. The terms used are Uplink and Downlink. Uplink is a method used to upload to the internet data read in real-time. In contrast, Downlink is used to request back server data that can be displayed on the computer in real-time before.
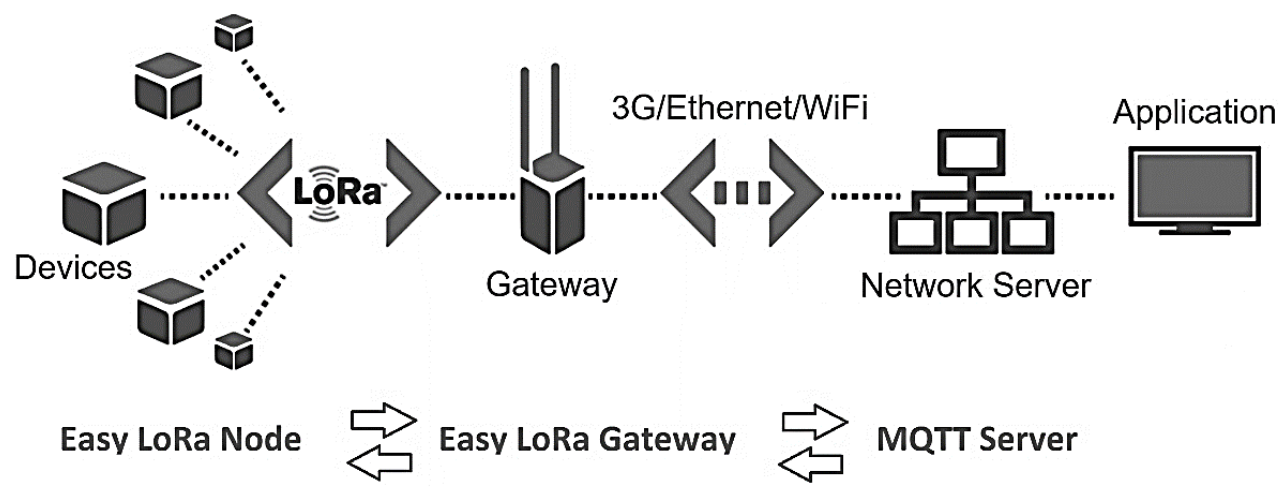

Fig. 1. Communication between LoRa End Node, LoRa Gateway, and MQTT Server

Moreover, MQTT or MQTT Broker works in the Publish, Subscribe process. The Publish process is carried out if MQTT Broker moves the sensor output from the end-node in this case, using the example of a thermometer. After MQTT Broker gets real-time data from end-nodes, this step continues on MQTT Publish, and devices used when sending end-node data to Computers or Mobile Devices as end-users; moreover, subscriptions is a reciprocal process from end-users to MQTT Broker. In some research, IoT is also referred to as ACK (Acknowledge) in communication between end-devices and MQTT Brokers and End Users.

\subsection{Irrigation, Agriculture Design and ADR Method}

Fig. 2(a) and Fig. 2(b) are the agricultural irrigation methods that farmers currently make; this irrigation is still conventional from year to year; indeed, this method continues to provide stable yields of shallots and garlic until now. When the dry season arrives, the curvature of the soil on irrigation can still store water well and make a simple fish pond. The water reservoir under the mound provides nutrients to the soil, and the plants are grown on it. But in today's era, many modern methods are offered for agriculture that doesn't take up space, such as using Hydroponics. Hydroponics is a type of agriculture that uses narrow land and does not use soil, only water. And in Hydroponic, a good nutrient is needed to grow healthy plants. Hydroponics can grow water, spinach, Pakcoy, spinach, and plants living in the water.

Several connected devices are used in automatic irrigation or irrigation, including Arduino microcontroller, LoRa $915 \mathrm{MHz}$ shield, $\mathrm{pH}$ water, turbidity sensor, Soil pH, soil Moisture, ultrasonic sensor, and Solar Cell, and Solenoid valve, as well as other supporting devices. These components are integrated to get an automatic system based on a microcontroller with LoRa telecommunication tools. LoRa $915 \mathrm{MHz}$, which is compatible with Arduino boards, will facilitate connectivity and data transmission with a small bit 
rate (125 kbps maximum data) to the LoRa Gateway; the rest will be sent to the Thingspeak or TTN Application Server. Ultimately can be seen in Fig. 3 and Fig. 4.

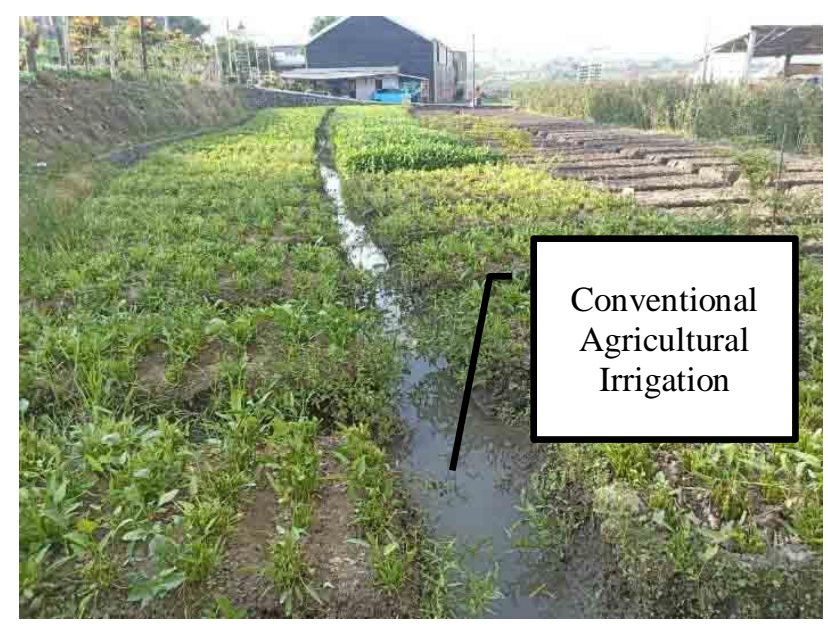

(a)

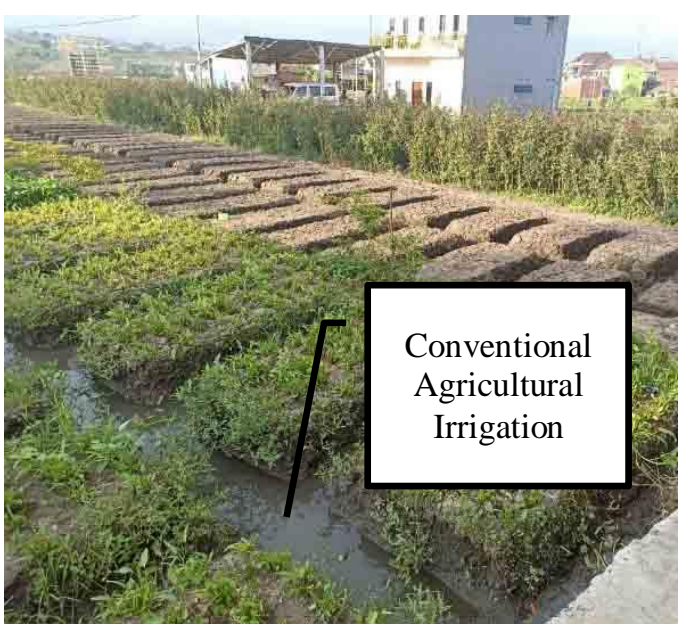

(b)

Fig. 2. (a), (b) Irrigation with traditional techniques

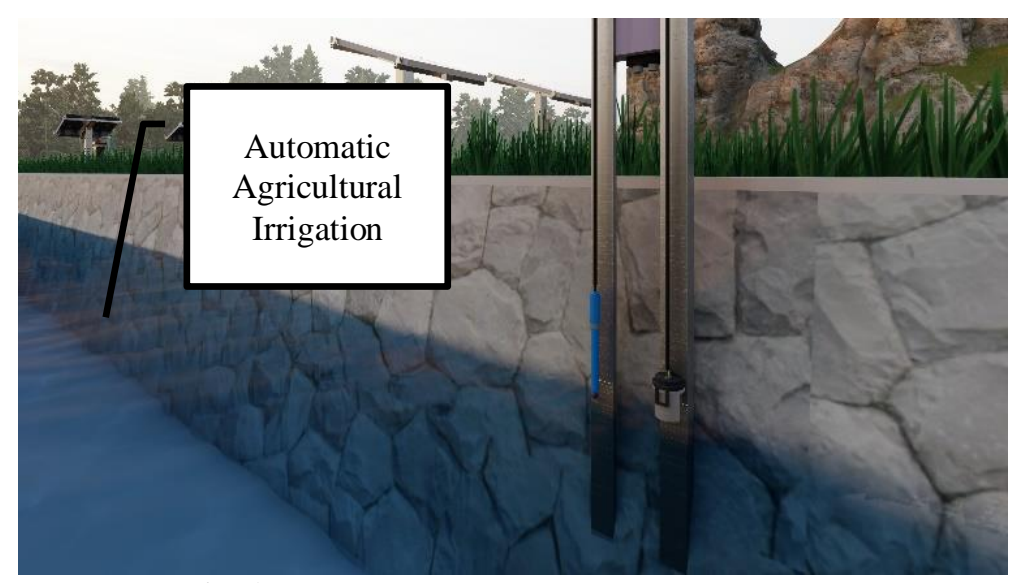

Fig. 3. Water $\mathrm{pH}$ sensor in river water reservoir

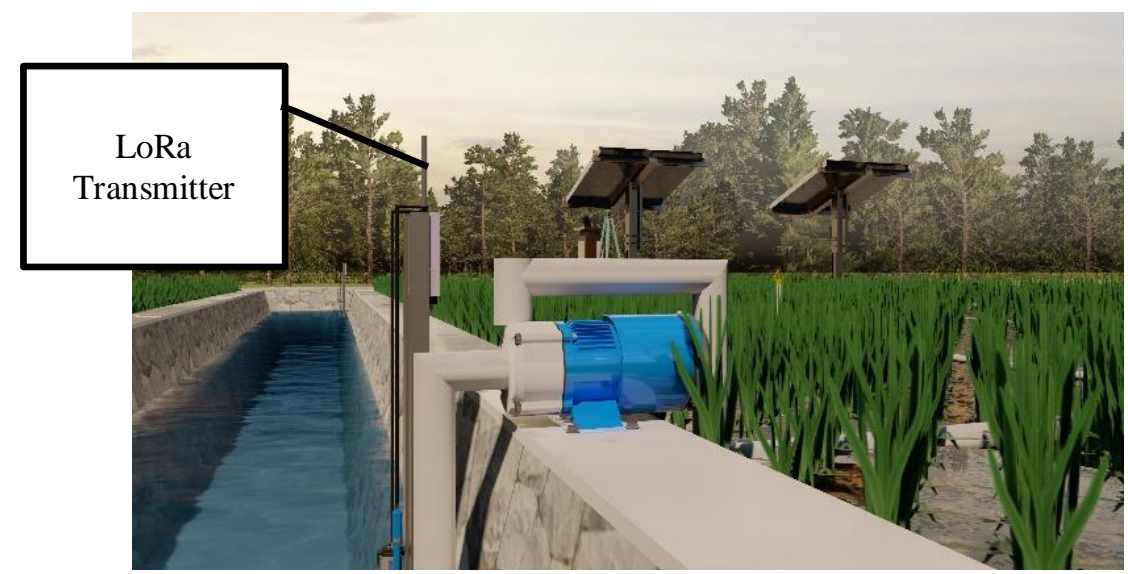

Fig. 4. Water pump used to deliver water to agricultural land

Soil $\mathrm{pH}$ and Soil moisture are two crucial input system components, and their function is to provide specific data on soil conditions and water conditions flowing into agricultural land. Suppose the soil moisture data shows dry soil. In that case, it can automatically provide feedback to the solenoid valve to open and drain water to the ground, similarly to the $\mathrm{pH}$ water sensor. It will provide feedback in the form of opening an acidic 
$\mathrm{pH}$ and alkaline $\mathrm{pH}$ tub that is ready to provide nutrients to the water so that the water returns to its normal $\mathrm{pH}$ position (6.5-7), which will provide good nutrition to plants in full can be seen in Fig. 5.

Furthermore, regarding the Algorithm or mechanism, it is essential for sending sensor data. This is because not only one sensor point placed, but many points, at least 10 points, will be sent to provide specific data at each point. So the right mechanism is the Adaptive Data Rate (ADR) mechanism; ADR is used to reduce packet loss and increase or stabilize throughput.

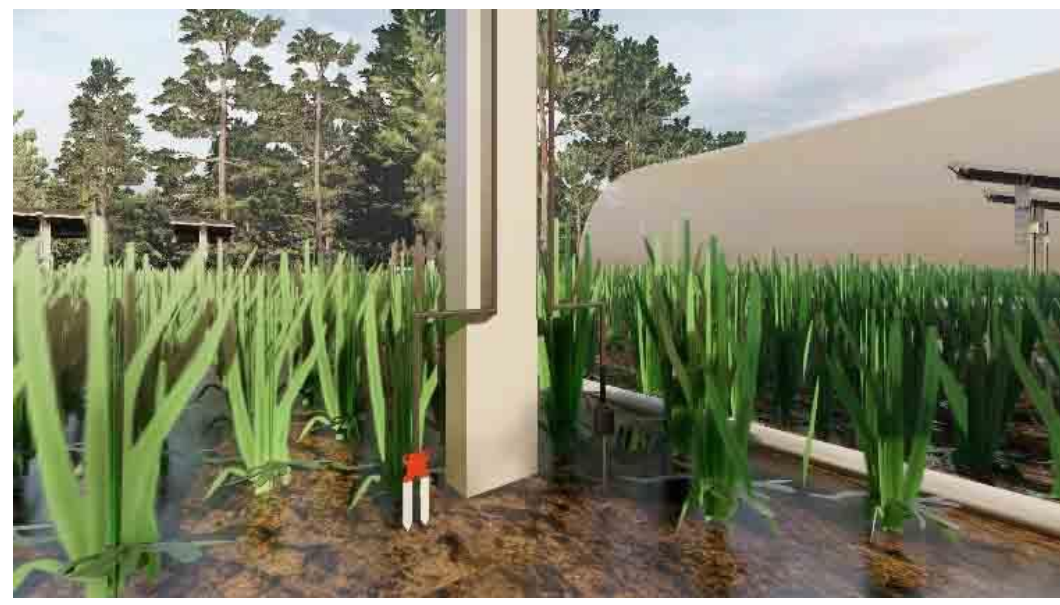

Fig. 5. input sensor for data preparing

Fig. 6 is a collection of tools integrated into automatic irrigation; this is one of the modern techniques, by combining energy harvesting from the sun, namely solar cells, converted to energy with smaller currents, namely 9-12 volt DC batteries. Which then provides power to each microcontroller without any electrical assistance at all. Then provide information from LoRa transceiver to internet without AC electricity connection. This is due to the location or location of the rice fields, which are far from electrical installations.

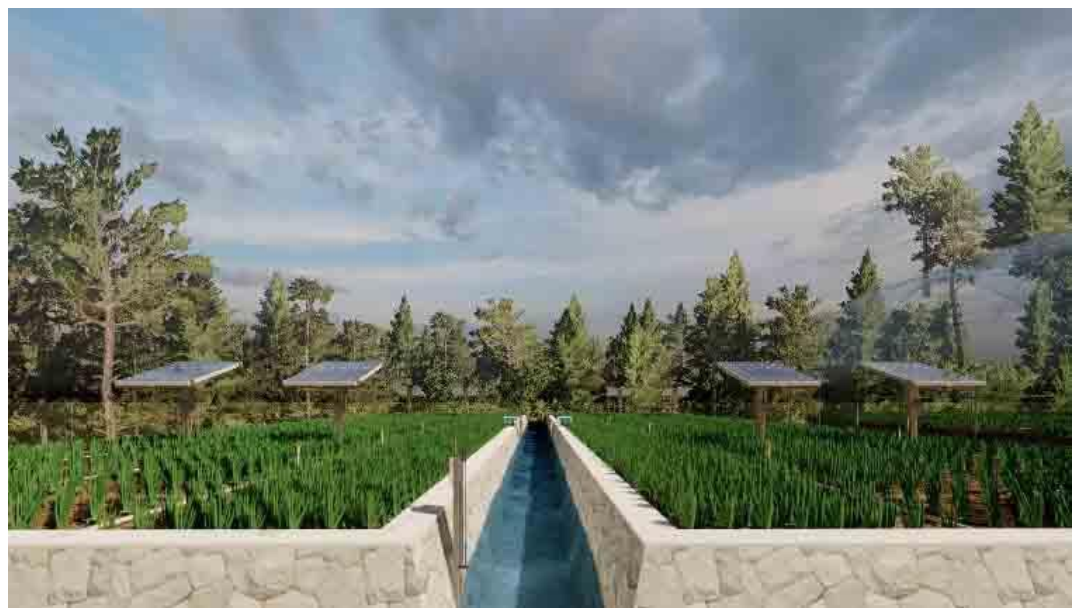

Fig. 6. Design of Automatic Irrigation

Meanwhile, the water in the irrigation basin is taken from a flowing river but is also equipped with a sensor that provides feedback to the solenoid valve to open and close the water valve from distance sensor data or ultrasonic sensor. The task of the ultrasonic sensor here is to provide information that the water is full and please close the solenoid valve automatically to let the water flow again, so the principle of taking water is based on ultrasonic sensor data regarding the volume of water that has reached the limit of the tub.

Fig. 7 is a design of LoRa transmitter [20][21][22][23][24][25][26][27], which is used to transmit or transmit sensor data via LoRa Dragino $915 \mathrm{MHz}$ [28][29][30]. This design is made like a pole with a height of 1-2 meters, with an Omni antenna type that can transmit data or beams in all directions; LoRa's ability to transmit electromagnetic signals is as far as $1 \mathrm{~km}-15 \mathrm{~km}$. with a note, that there are no obstacles. Obstacles that exist include trees, buildings, bad weather (heavy rain, fog). Attenuation due to bad weather is shown in the results and analysis chapter. 

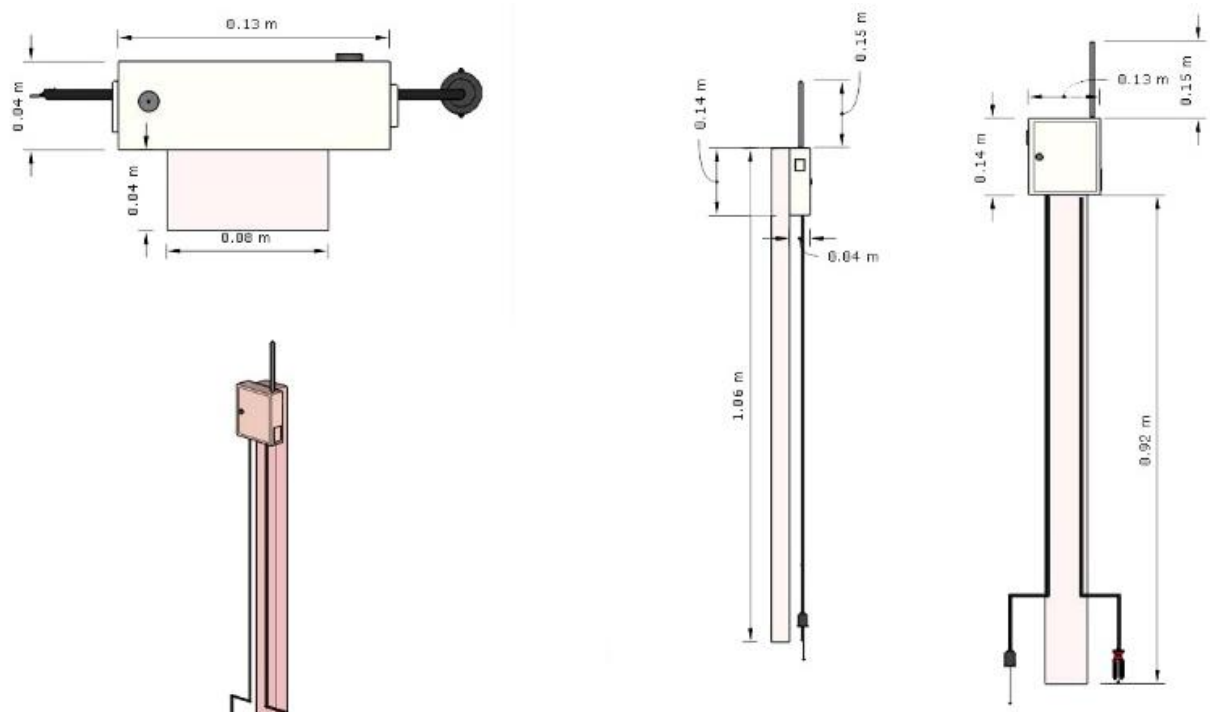

Fig.7. LoRa Transmitter Design

Fig. 8 shows the LoRa Master-Slave method, this type of method has a drawback, namely MIMO does not work well, which only has Multiple outputs, but for Multiple inputs, this does not happen. Multiple inputs in question are the number of receivers available to serve the number of transmitters that send data at once at a certain time. Therefore, the development of ADR can be seen in Fig. 9. Fig. 9 shows the minimized MIMO concept that occurs. However, the number of receivers is still not as many as transmitters. This is called the Adaptive Data Rate (ADR) strategy because having at least 2 or 3 receivers is better than just one receiver, which causes a data bottleneck that causes a significant packet loss.

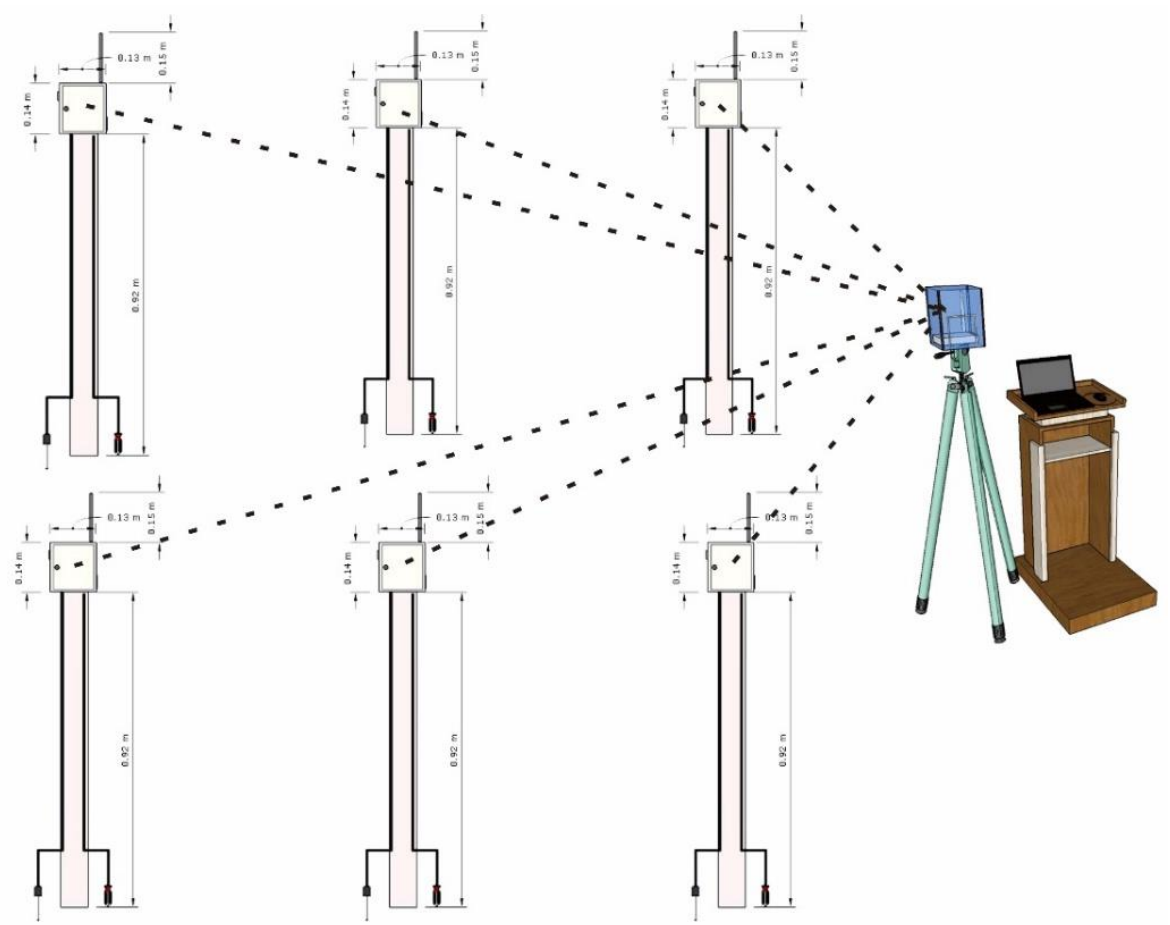

Fig. 8. LoRa Master-Slave method 


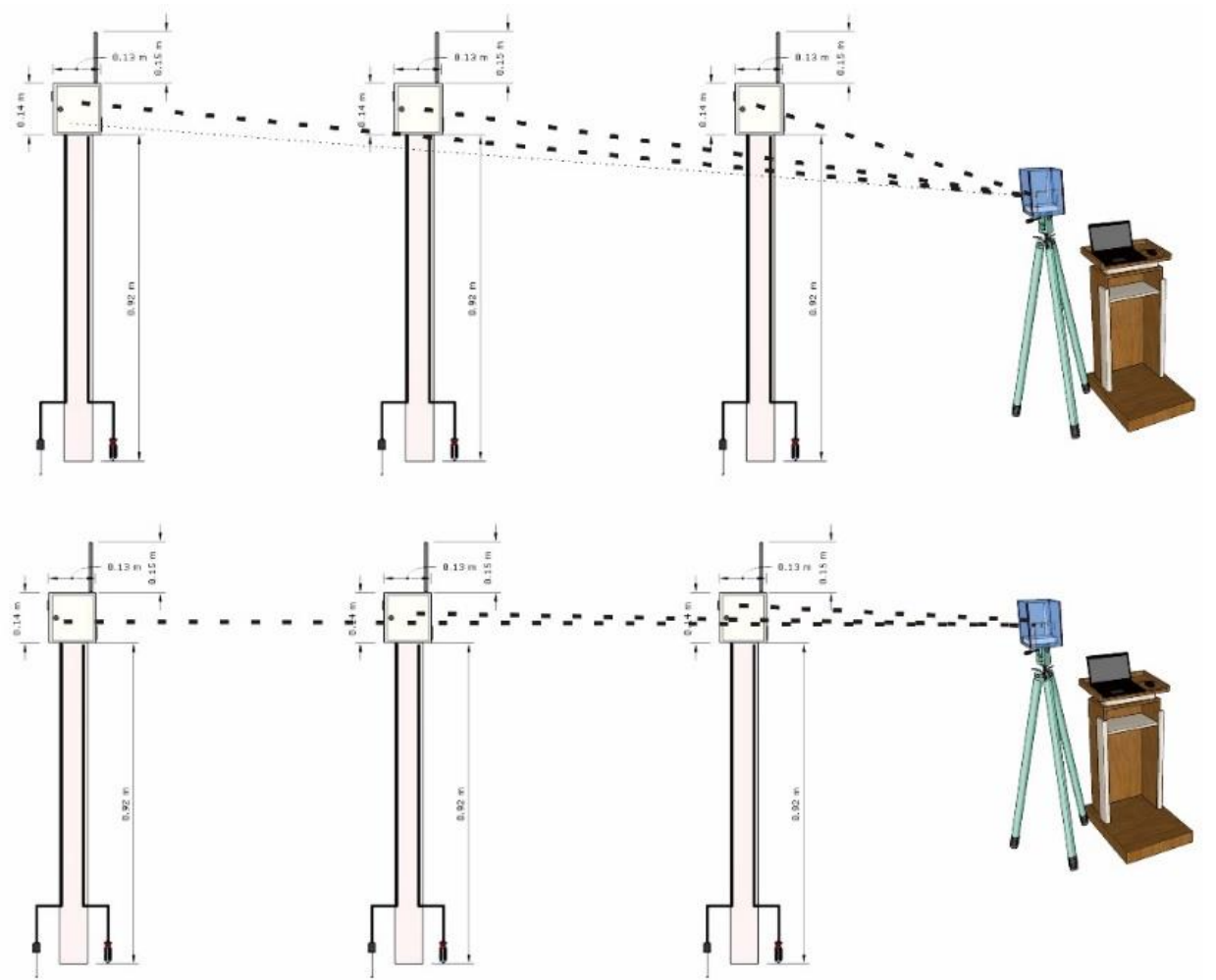

Fig. 9. ADR Mechanism

Furthermore, Table 1 is the specification of LoRa, which is essential which determine LoRa's ability to transmit data. The spreading Factor in LoRa is 7-12 with a bandwidth of $125 \mathrm{kHz}$. And only 1 uses a bandwidth (BW) of $250 \mathrm{kHz}$, with a spreading factor of 7 and a bit rate of $11 \mathrm{kbps}$. Spreading Factor talks about the distance from Transmitter (Tx) to Receiver $(\mathrm{Rx})$. The faster the transmitting distance of radio waves from Tx to $\mathrm{Rx}$, the throughput is greater than the farther Tx and Rx. This is due to attenuation, we can see in table 1 with Spreading Factor 7 with $250 \mathrm{kHz}$ BW with Bit Rate $11 \mathrm{kbps}$ and Spreading Factor $(S F) 12$ with BW 250 bps, this is a significant difference. While Fig. 10 is one of the basics of $S F$ and the energy expended, when viewed from the Bitrate, the farther the distance, the Bitrate decreases, and energy or Time on Air (ToA) increases.

Table 1. LoRa Data Rate and Spreading Factor

\begin{tabular}{cccc}
\hline Index & Spreading Factor (SF) & Bandwidth (BW) & Bit Rate (bps) \\
\hline 0 & 12 & $125 \mathrm{kHz}$ & $250 \mathrm{bps}$ \\
\hline 1 & 11 & $125 \mathrm{kHz}$ & $440 \mathrm{bps}$ \\
\hline 2 & 10 & $125 \mathrm{kHz}$ & $980 \mathrm{bps}$ \\
\hline 3 & 9 & $125 \mathrm{kHz}$ & $1760 \mathrm{bps}$ \\
\hline 4 & 8 & $125 \mathrm{kHz}$ & $3125 \mathrm{bps}$ \\
\hline 5 & 7 & $125 \mathrm{kHz}$ & $5470 \mathrm{bps}$ \\
\hline 6 & 7 & $250 \mathrm{kHz}$ & $11000 \mathrm{bps}$ \\
\hline
\end{tabular}

Eq. (1)-(14) is an important formula used by LoRa to determine LoRa's Quality of Service (QoS) when the testbed is real in the field or simulated. Many LoRa simulations currently use OMNET++ with fLORA and MatLab with CSS (Chrips Spread Spectrum) analysis. However, the equations (1)-(14) are needed for the analysis needs, e.g., in determining ToA, SNR (-dB), CR, SF, Rs, Rc, and RSSI (-dBm).

$$
\begin{gathered}
\text { ToA }=T_{\text {Preamble }}+T_{\text {Payload }} \\
T_{\text {preamble }}=\text { Nb Preamble }(8)+\text { symbols added by radio }(4.25) \times \text { Tsymbol } \\
T_{\text {payload }}=\text { NbPayloadSymbol } \times \text { Tsymbol }
\end{gathered}
$$




$$
\begin{aligned}
& n_{\text {payload }}=8+\max \left(\operatorname{ceil}\left[\frac{(8 P L-4 S F+28+16 C R C-20 I H)}{4(S F-2 D E)}\right](C R+4), 0\right) \\
& S N R(d B)=\frac{E_{b}}{N_{o}}+10 . \log _{10}\left(R_{S}\right)+10 . \log _{10}(k)+10 . \log _{10}(R)-10 . \log _{10}\left(B W_{n}\right) \\
& C R=4 /(4+n) \\
& S F=\log _{2}\left(\frac{R c}{R S}\right) \\
& R s=\frac{1}{T S} \\
& \mathrm{Rs}=\frac{\mathrm{BW}}{2^{\mathrm{SF}}}=\frac{\mathrm{Rc}}{2^{\mathrm{SF}}} \quad \text { symbols } / s \\
& R c=2^{S F} R b \\
& R c=2^{S F} R S \\
& R c=B W \text { chips } / s \\
& \operatorname{RSSI}(\mathrm{dBm})=10 \log (\operatorname{Pr}) \\
& R S S I(-d B m)=-(10 N \log 10 d+A)
\end{aligned}
$$

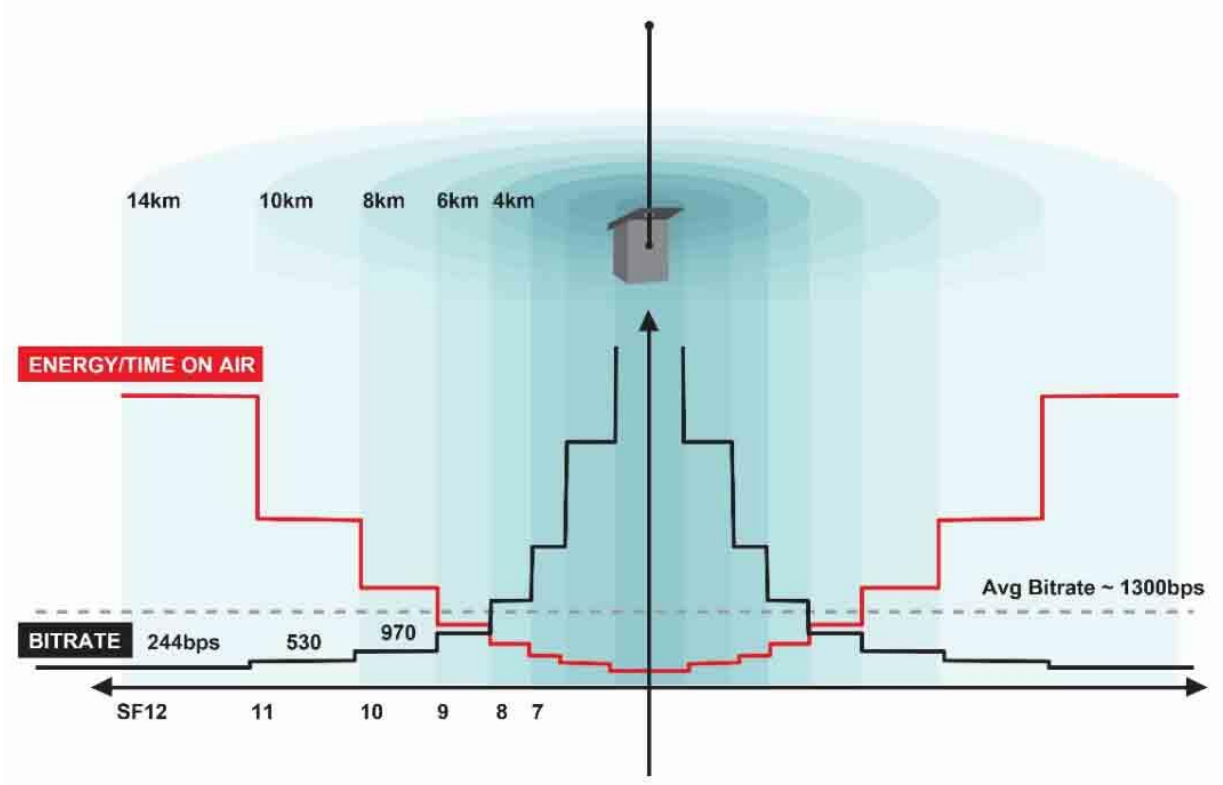

Fig. 10. Energy of LoRa

Fig. 11 is the Connectivity of the Turbidity sensor and Arduino Mega. Fig. 12 shows the Connectivity of the Solenoid valve, Arduino Mega, six-channel relay, and DC motor. In Fig. 11, the Turbidity sensor is used to detect the level of water turbidity. In the system being built, if the level of turbidity of the water is high, then the water cannot flow to the next tub. Therefore, it can be added to absorb water turbidity factors such as rocks and alum. Furthermore, in Fig. 12, the solenoid valve opens and closes the water faucet that will flow into the next tub. This solenoid valve provides acid and base if the water conditions are classified as acidic or alkaline. Fig. 13. is Automatic control of watering on plants. 


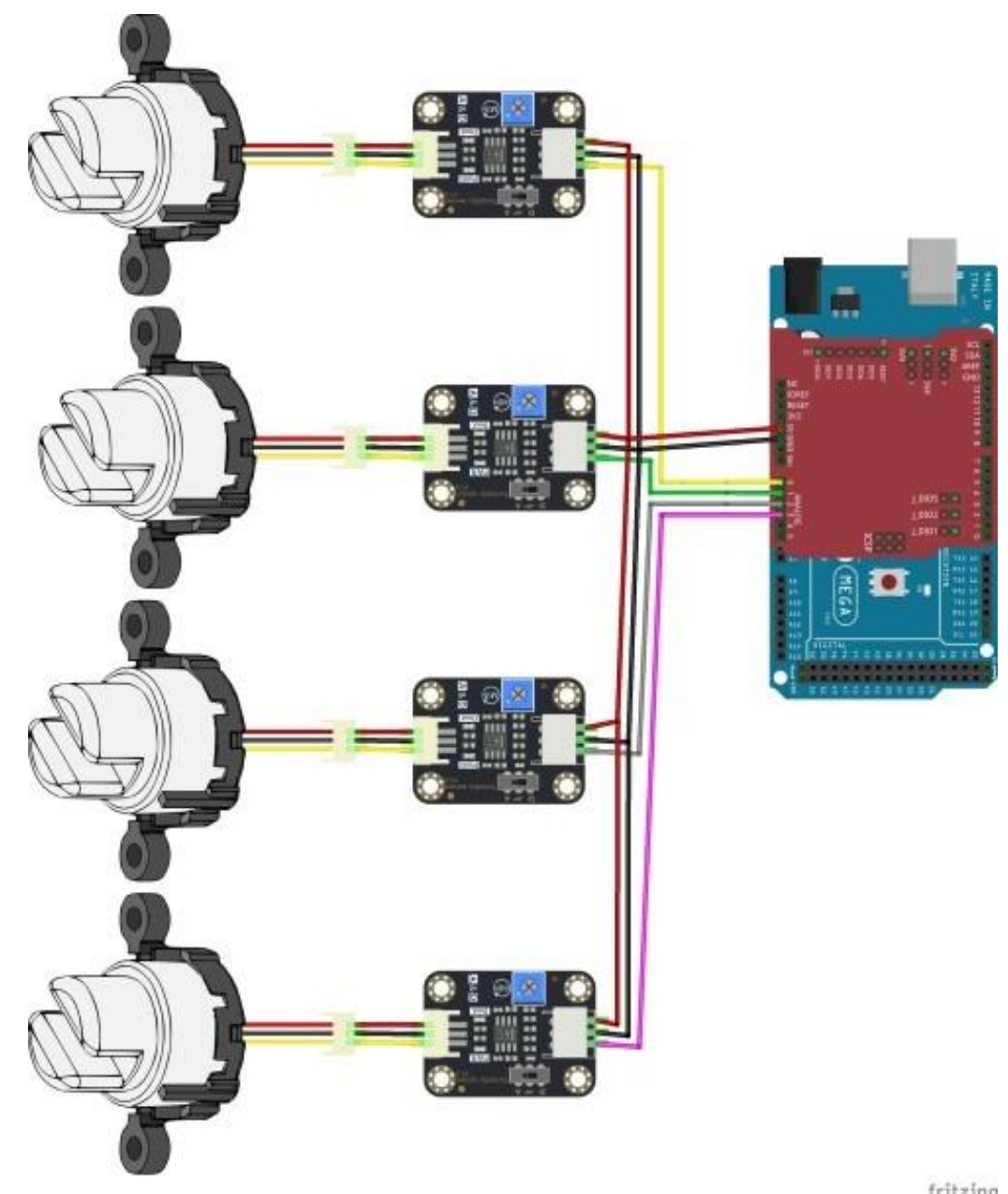

Fig. 11. Connectivity of Turbidity sensor and Arduino Mega

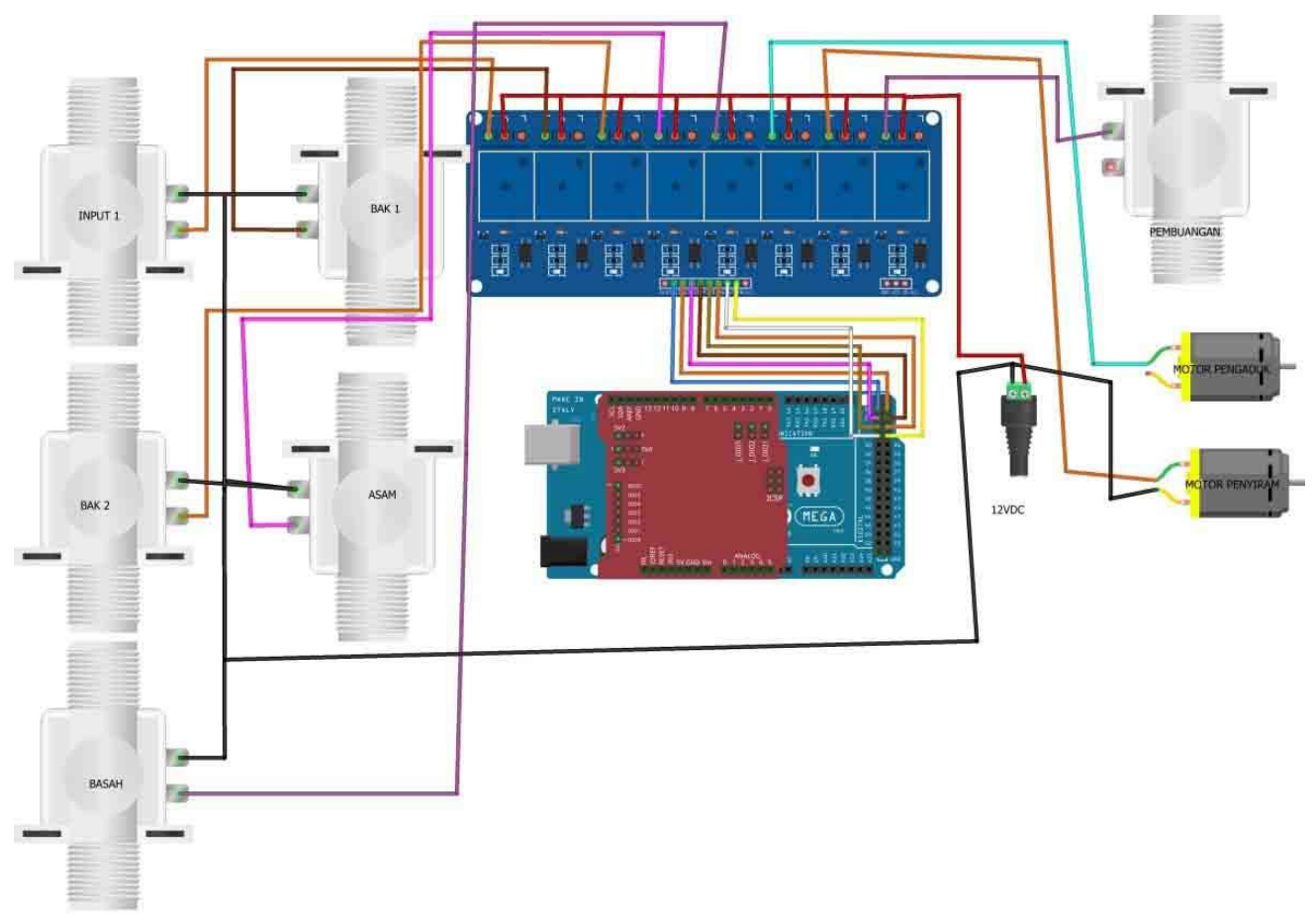

Fig. 12. Connectivity of Solenoid valve, Arduino Mega, relay six-channel, and motor DC 


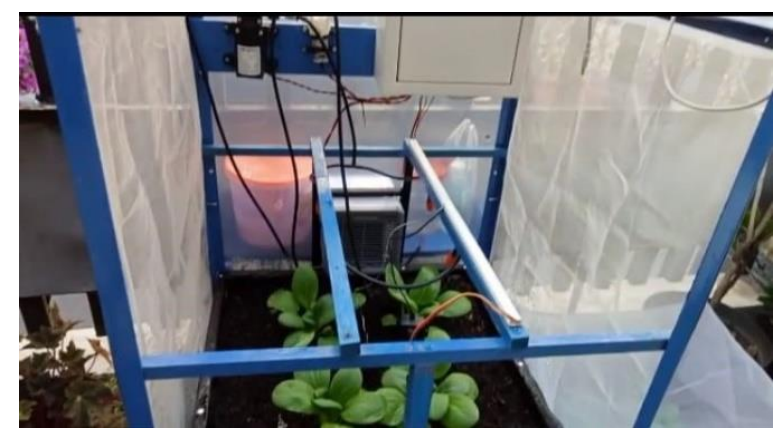

(a)

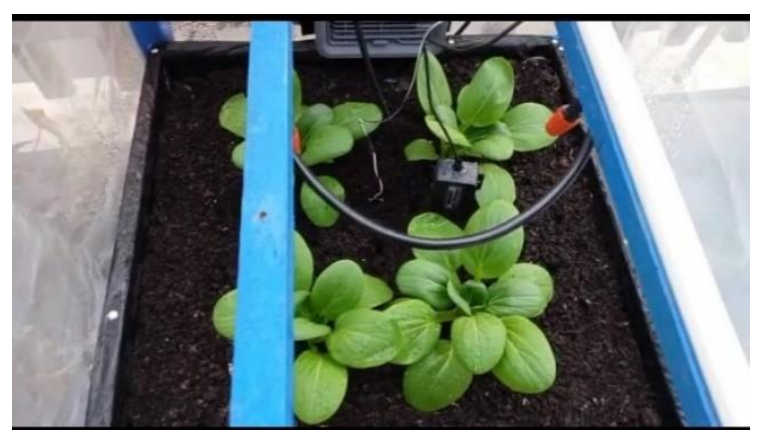

(b)

Fig. 13. (a), (b) Automatic control of watering on plants

\section{RESULTS AND DISCUSSION}

ADC Sensor and output voltage are sensor outputs from sensors that show changes in the volume of water, specifically shown in Fig. 14, Fig. 15, and Fig. 16. The higher the ADC Sensor, the higher the output voltage (volt DC). Another instrumentation is shown in Fig. 15, where the scale decreases as the ADC Sensor 1000 increases, and the scale decreases to 2 from a scale range of 2-10. Next, in Fig. 16, the ADC sensor decreases with increasing water volume (ml); e.g., the ADC sensor shows a decrease from ADC 1000 to 200.

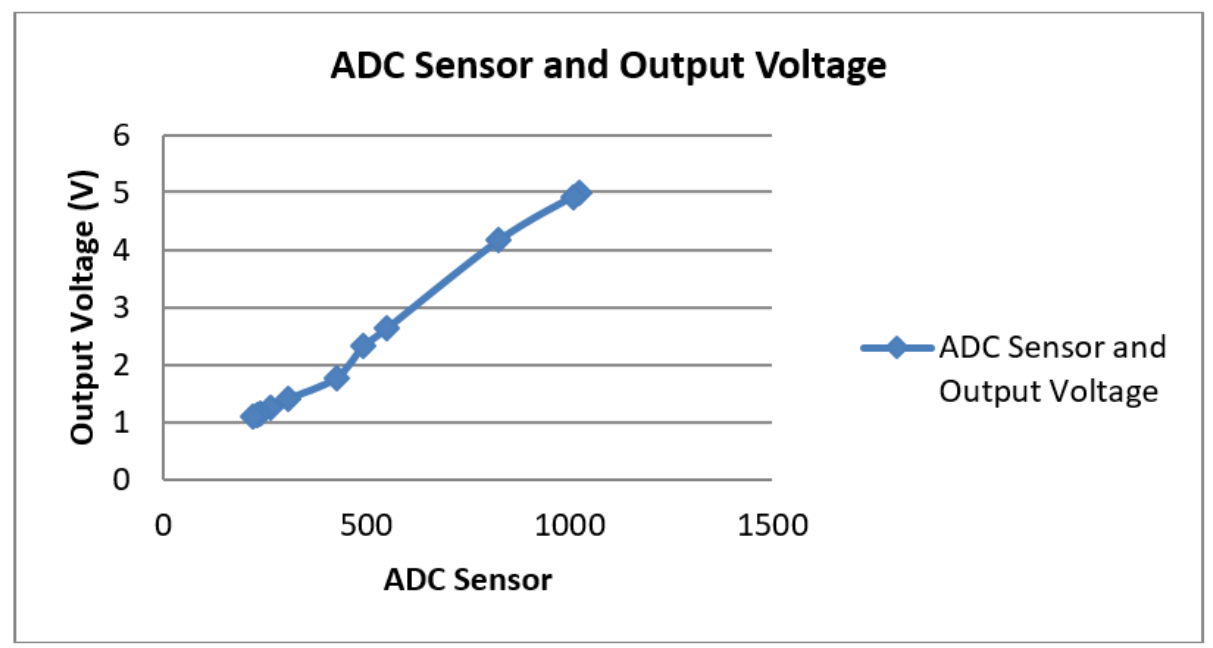

Fig. 14. ADC Sensor and Output Voltage (Volt DC)

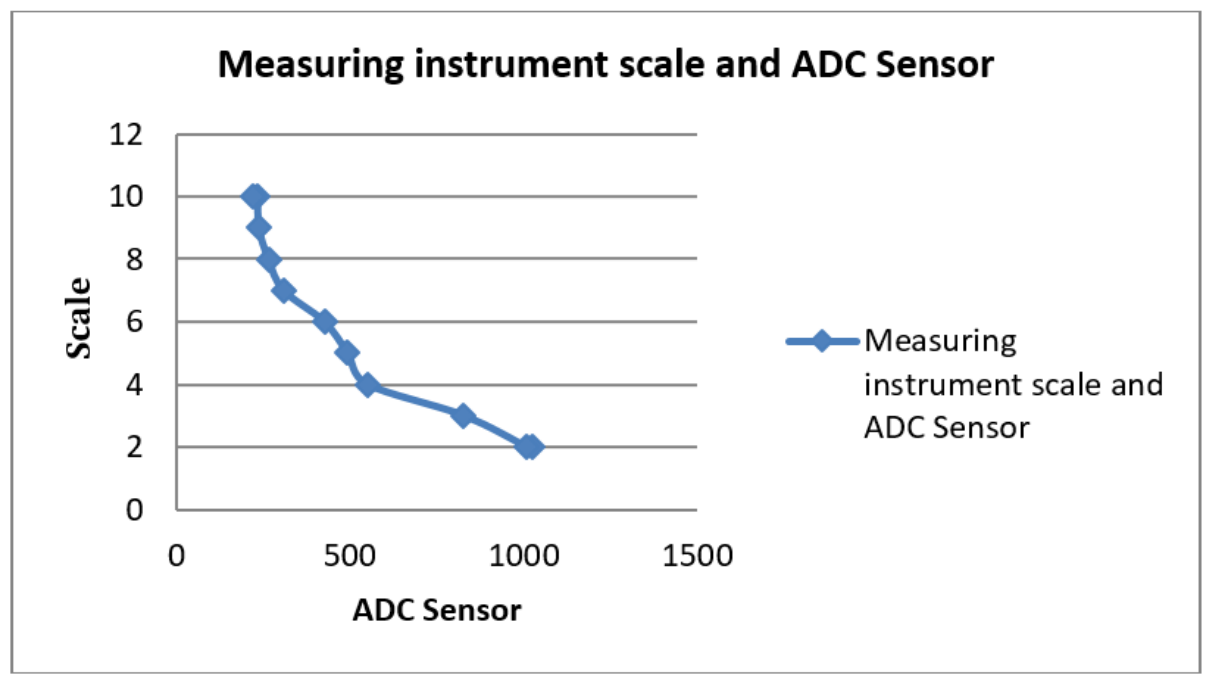

Fig. 15. A Measuring instrument scale and ADC Sensor 


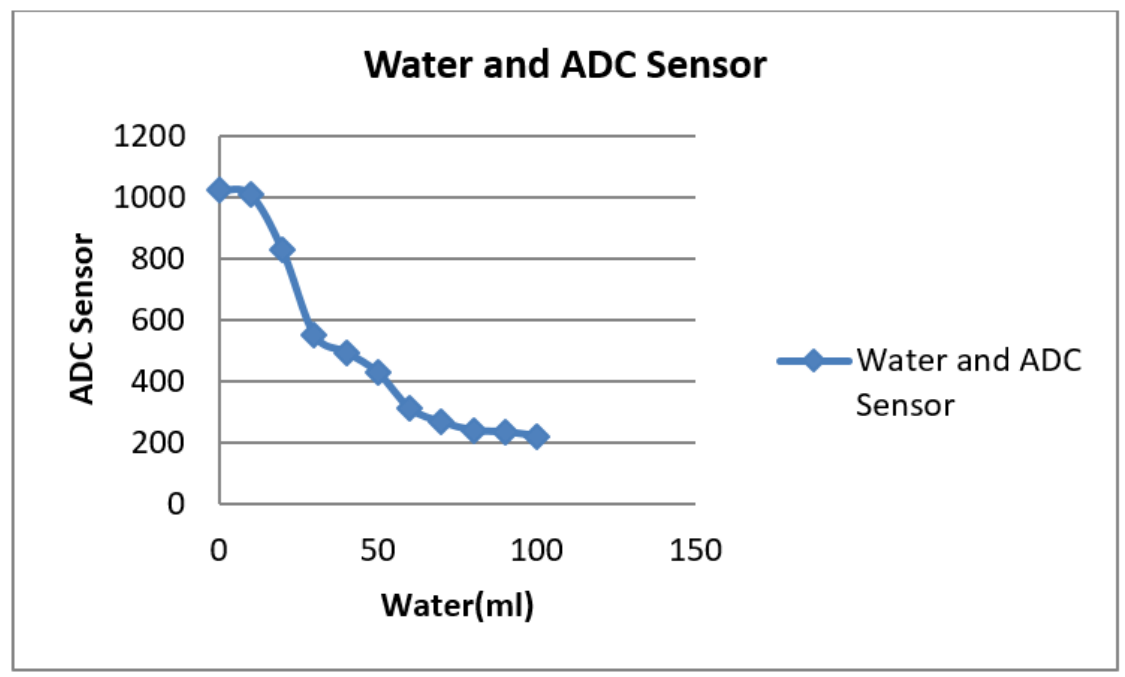

Fig. 16. Water and ADC Sensor

Fig. 17 and Fig. 18 are a comparison between the DHT11 sensor and the thermometer at midday and night; it can be seen that there is no significant difference between the DHT11 and the thermometer. But in general, the temperature at night is cooler than the temperature during the day. Therefore, the temperature during the day ranges from 30-35 degrees Celsius, and the temperature at night ranges from 22-23 degrees Celsius.

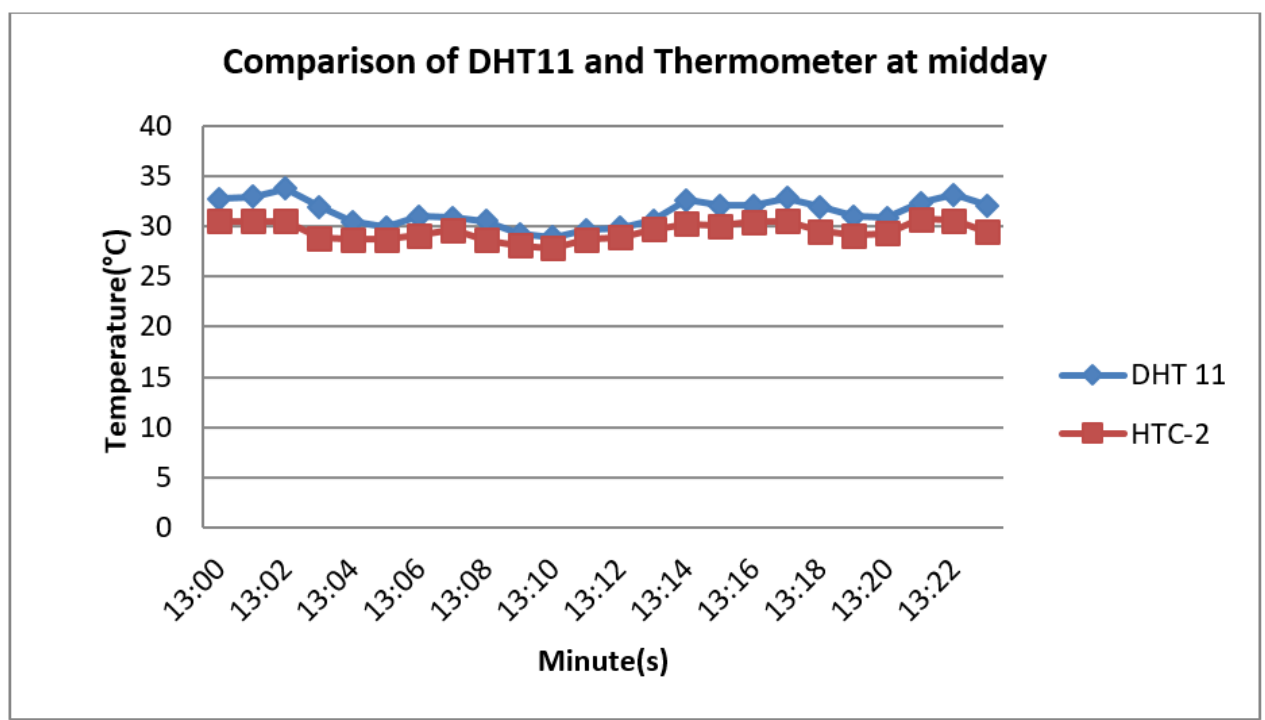

Fig. 17. Comparison of DHT11 sensor and Thermometer at midday

Fig. 19, Fig. 20, and Fig. 21 are the output of the Thingspeak Application Server of all sensors used in this research. Sensors include pH sensors, temperature (DHT11) sensors, Humidity sensors, and other sensors connected to this system or analysis. Furthermore, Fig. 22 is a Real-time Temperature Indicator, Humidity Indicator, and $\mathrm{pH}$ [25] Indicator in the form of a temperature indicator using color, so it can be seen that if the color shows red, it means high temperature; otherwise, if it is green, it means low temperature.

Furthermore, Fig. 23 is the analyzer result if there is LoRa data transmitting, then the signal shows an oscillation or increase in amplitude at the centerline analyzer in Fig. 23 (c); otherwise, if there is no LoRa data transmitting, then there is no signal like Fig. 23(b), while Fig. 23(a) and Fig. 23(c) are the same because both LoRa signals are detected. The greater the ToA or, the greater the SF or, the greater the energy or, the farther the distance between $\mathrm{Tx}$ and $\mathrm{Rx}$, the weaker the signal will mean (-dB the greater the value). 


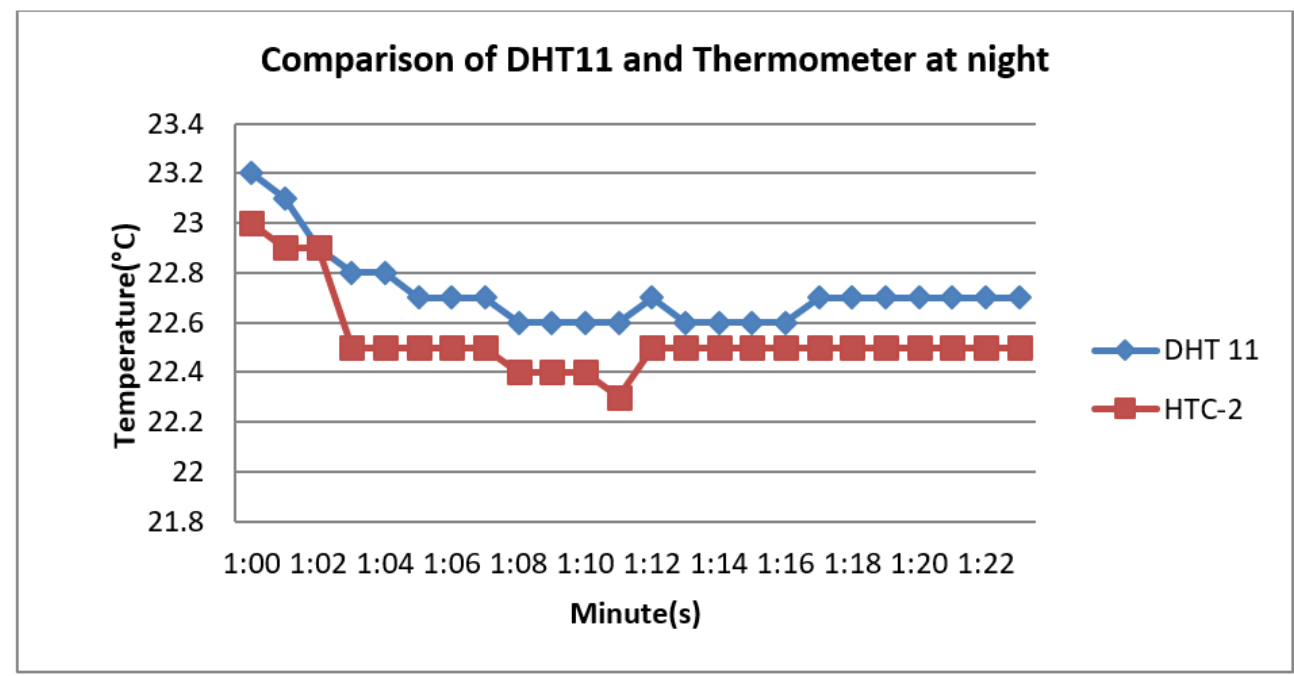

Fig. 18. Comparison of DHT11 sensor and Thermometer at night

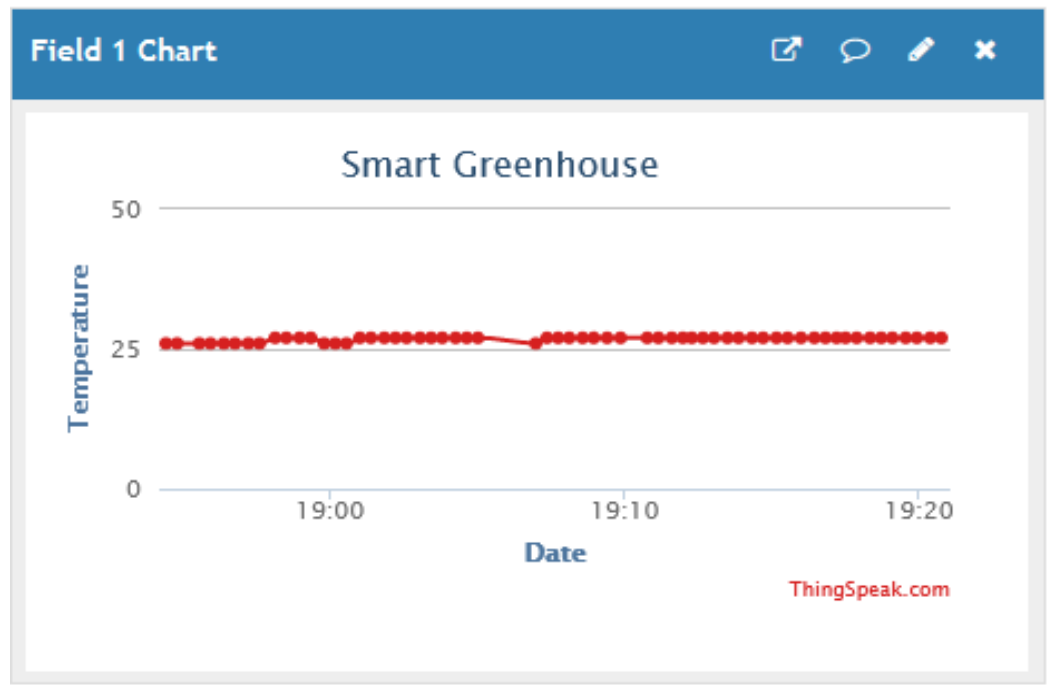

Fig. 19. Realtime data Temperature

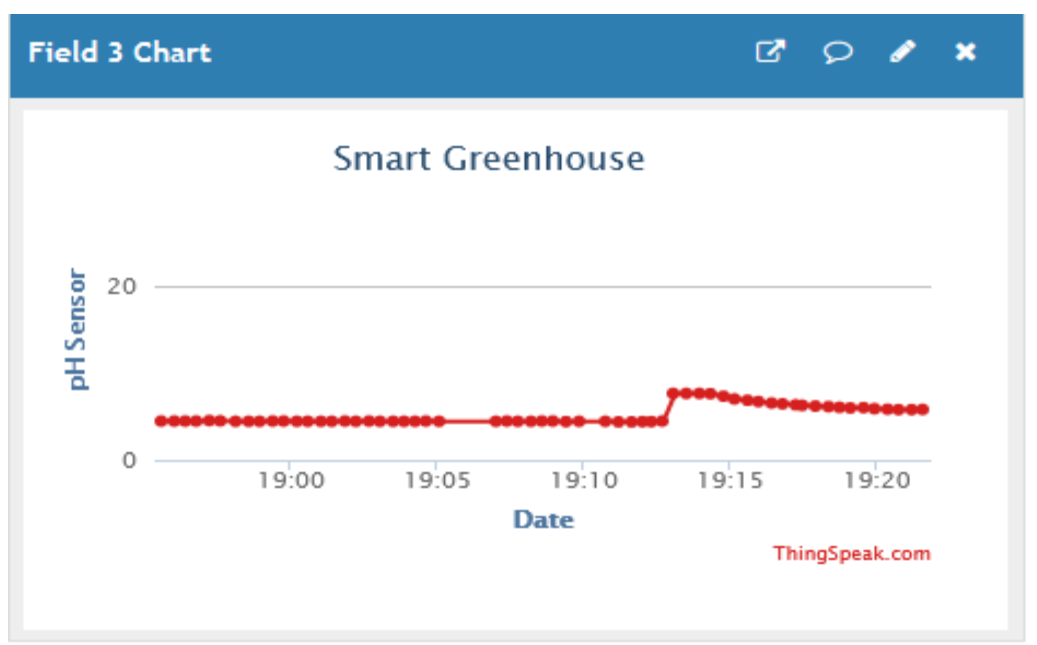

Fig. 20. Realtime data $\mathrm{pH}$ 


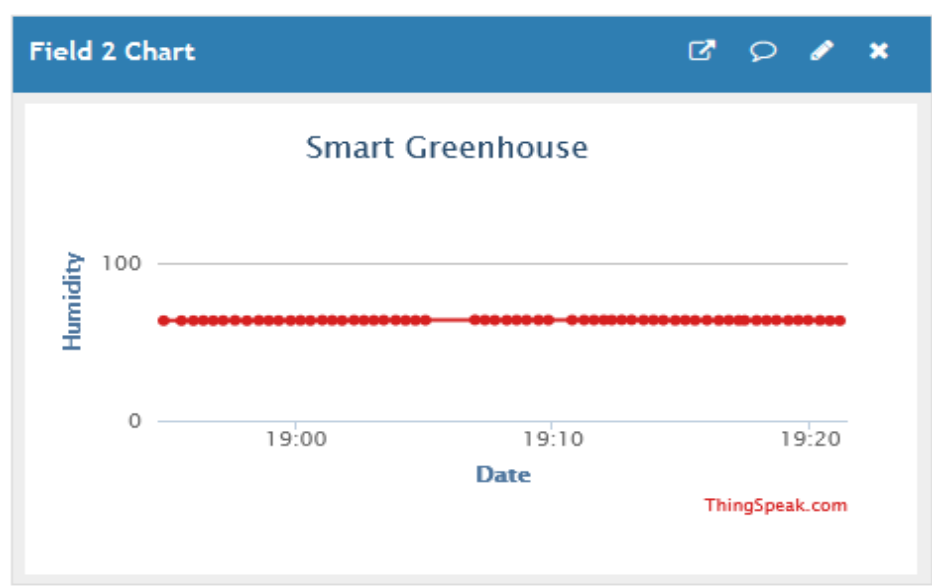

Fig. 21. Realtime data Humidity

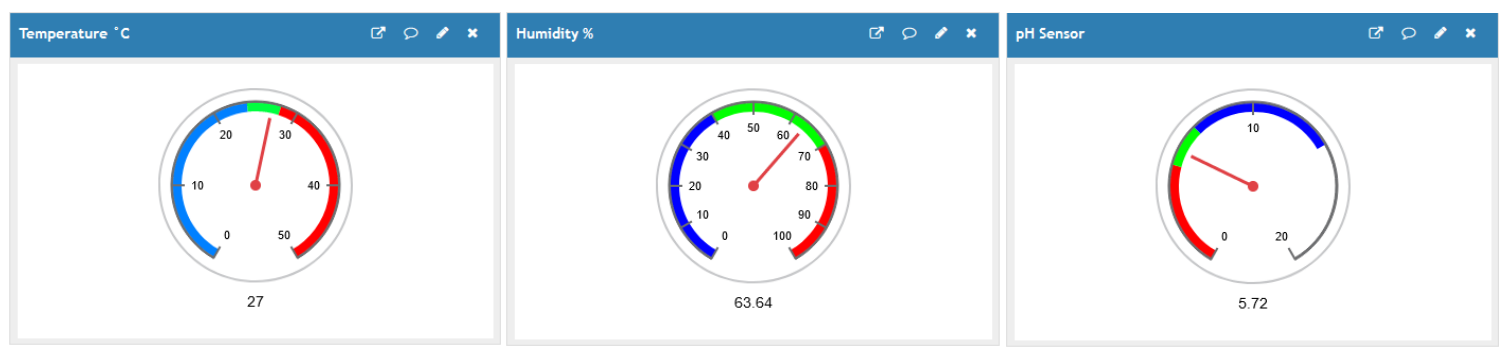

Fig. 22. Realtime Temperature Indicator, Humidity Indicator, and pH Indicator

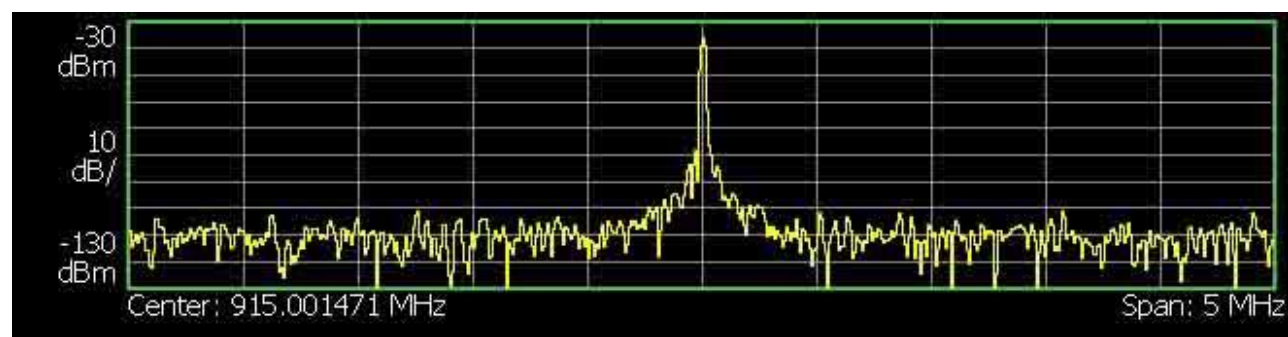

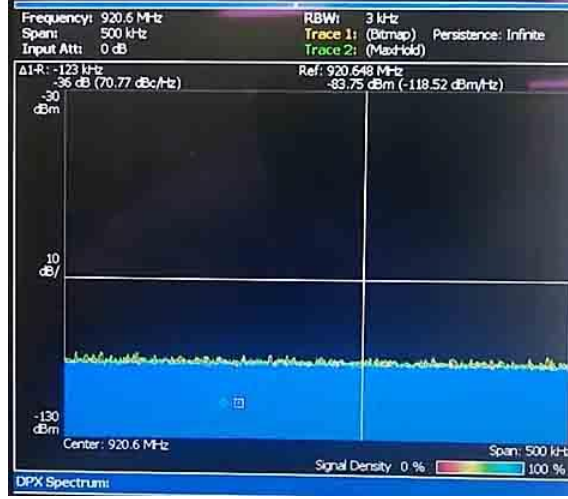

(b)

(a)

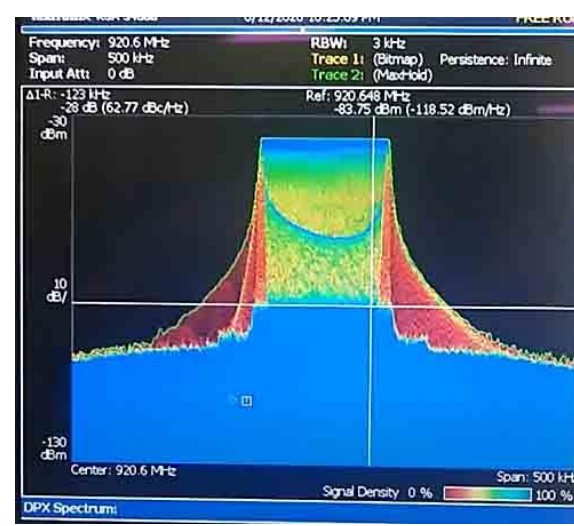

(c)

Fig. 23. (a, b, c) Realtime monitoring from LoRa signal analyzer

Furthermore, Fig. 24 is the LoRa Receive Signal Strength Indicator (-dBm) at a certain distance, represented in 1 meter. It can experience attenuation if the distance is added. In Fig. 24, the best value is shown in the RSSI on analyzer 2, which is $-34 \mathrm{dBm}$ to $-36 \mathrm{dBm}$; this is a good result meaning it has excellent signal strength, which may also decrease if the distance of the transceivers moves away from each other; furthermore, Fig. 25 is an example of a decrease in the Receive Signal Ratio (\%) if the distance increases, the signal-noise ratio $(\%)$ decreases, at a distance of $1 \mathrm{~km}$. Without obstacles reached $93.945 \%$. 


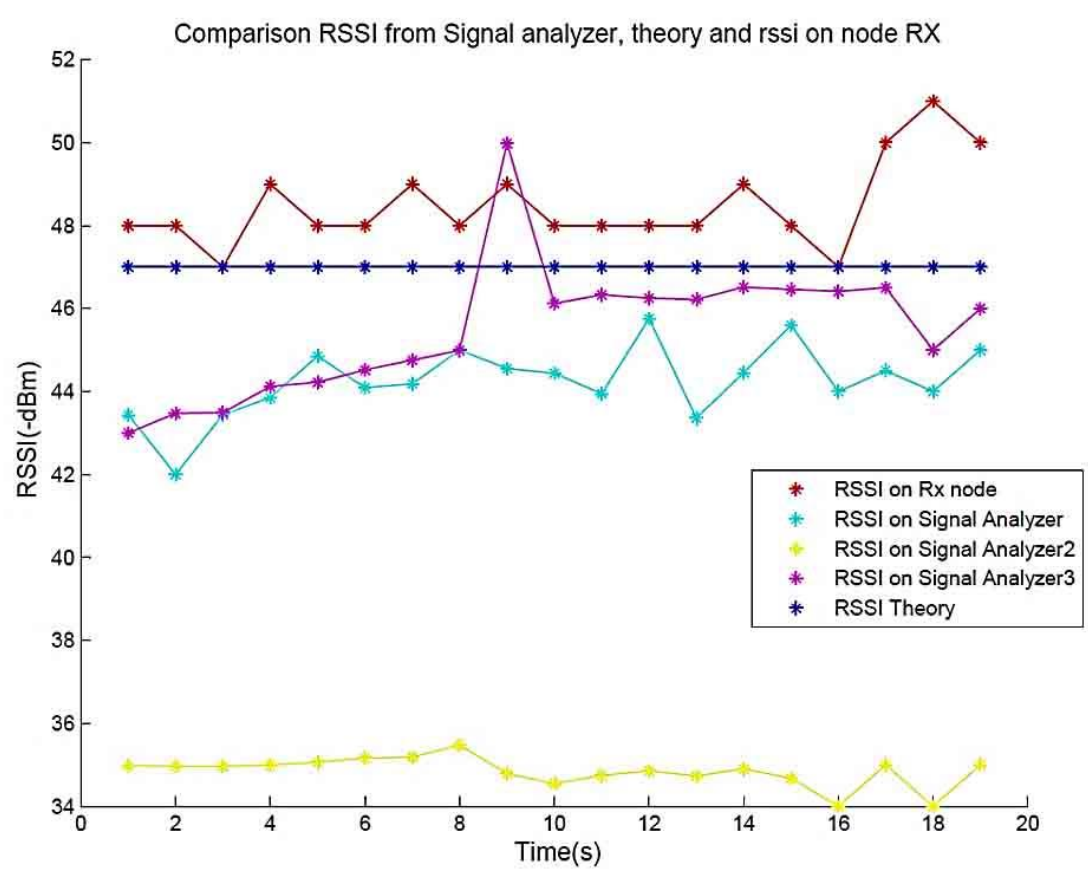

Fig. 24. LoRa Receive Signal Strength Indicator (-dBm)

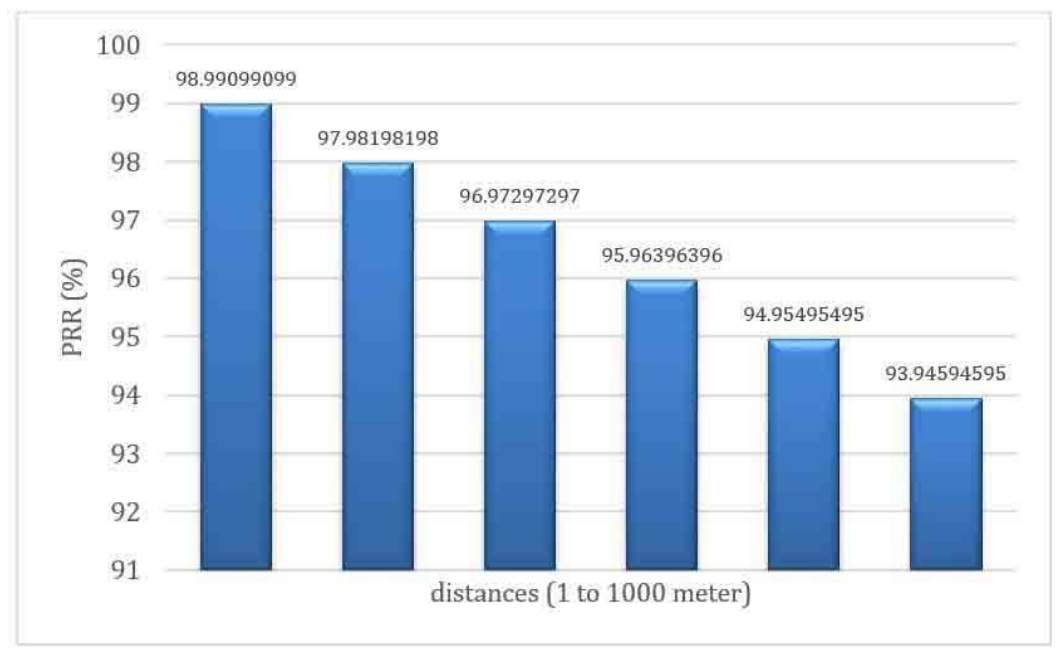

Fig. 25. LoRa Packet Receive Ratio (\%) at $1 \mathrm{~km}$

Next is Fig. 26. It is the Attenuation LoRa signal on the heavy rain. LoRa signal decreased to $-140 \mathrm{dBm}$. It was initially around $-65 \mathrm{dBm}$ to $-70 \mathrm{dBm}$ at a distance of $1 \mathrm{~m}$ to 100 meters. And at a distance of $1 \mathrm{~km}$, it reaches $-140 \mathrm{dBm}$ in heavy rain conditions, while drizzle and normal conditions are not too significant at a distance of $1 \mathrm{~km}$ is $-120 \mathrm{dBm}$.

\section{CONCLUSION}

All sensors work well; for example, the temperature sensor with temperature test equipment has been functioning and compared well with minimal errors. The test shows the temperature during the day ranges from 30-35 degrees Celsius, and the temperature at night ranges from 22-23 degrees Celsius. Next, sensor testing by looking at ADC Sensor values has shown specific changes. In addition, in LoRa signal testing, it can be seen that the resulting signal can be analyzed explicitly using Textronix's LoRa Signal Analyzer and shows a decrease in the Receive Signal Ratio (\%). If the distance increases, the signal-noise ratio (\%) decreases at a distance of $1 \mathrm{~km}$. Without obstacles reached 93.945\% - the Attenuation LoRa signal on the heavy rain. LoRa signal dropped to $-140 \mathrm{dBm}$. It was initially around $-65 \mathrm{dBm}$ to $-70 \mathrm{dBm}$ at a distance of $1 \mathrm{~m}$ to 100 meters. And at a distance of $1 \mathrm{~km}$, it reaches $-140 \mathrm{dBm}$ in heavy rain conditions, while drizzle and normal conditions 
are not too significant at a distance of $1 \mathrm{~km}$ is $-120 \mathrm{dBm}$. And the output ADC values of all sensors can be seen in real-time via the Thingspeak Application Server. In general, the whole research is going well from the prototype side and its working system, from the sensory side, starting from the LoRa signal analyzer, and the testing of the sensor is going well during testing. Still, one or two things that have happened are that they have not been specifically and in-progress - testing the entire system at the research location, and it is still using prototypes and test equipment outside the study room or research or research test place.

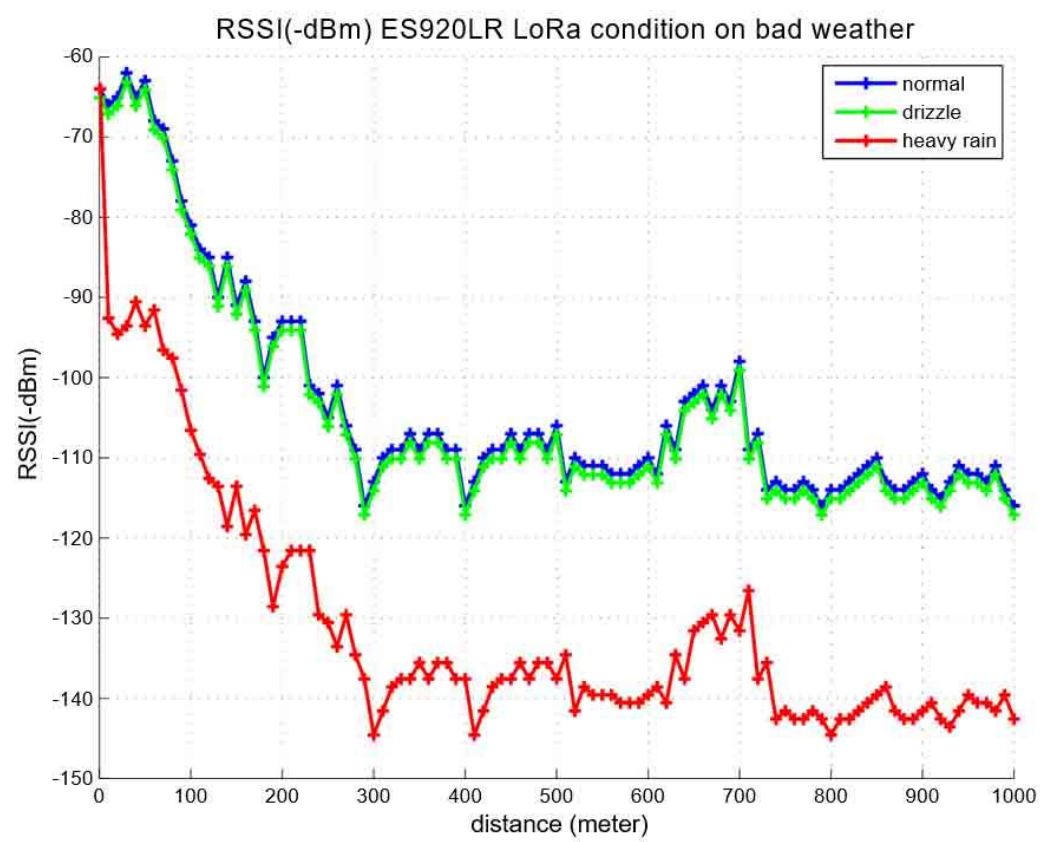

Fig. 26. Attenuation LoRa signal on the heavy rain

\section{Acknowledgments}

Thank you to all the research teams who have helped in data collection, measuring, making prototypes, testing, LoRa testbeds, and comprehensive testing of this one system, thanks to the national research institute through DIKTI, which has helped through PTUPT funding. Thanks to LPPM University of Merdeka Malang as the funding coordinator for the PTUPT, and thanks to all parties at the University of Merdeka Malang, especially the Electrical Engineering Study Program at the University of Merdeka Malang.

\section{REFERENCES}

[1] A. Gehani, S. Harsha Shatagopam, R. Raghav, M. Sarkar, and C. Paolini, "Application of 915 MHz Band LoRa for Agro-Informatics," 2021 Wireless Telecommunications Symposium (WTS), 2021, pp. 1-4. https://doi.org/10.1109/WTS51064.2021.9433712

[2] A. K. Junejo, F. Benkhelifa, B. Wong and J. A. McCann, "LoRa-LiSK: A Lightweight Shared Secret Key Generation Scheme for LoRa Networks," in IEEE Internet of Things Journal. https://doi.org/10.1109/JIOT.2021.3103009

[3] A. Marquet, N. Montavont, and G. Z. Papadopoulos, "Investigating Theoretical Performance and Demodulation Techniques for LoRa," 2019 IEEE 20th International Symposium on "A World of Wireless, Mobile and Multimedia Networks" (WoWMoM), 2019, pp. 1-6. https://doi.org/10.1109/WoWMoM.2019.8793014

[4] C. Baydur and S. Sahin, "ARM-Based Smart Water Meter with LoRa for Soilless Agriculture Application", European Journal of Science and Technology, June 2021. https://doi.org/10.31590/ejosat.957639

[5] D. Sumanth, "LoRa based Wireless Weather Station," International Journal for Research in Applied Science and Engineering Technology (IJRASET), June 2021. https://doi.org/10.22214/ijraset.2021.35289

[6] E. Kökten, B. C. Çalışkan, S. Karamzadeh, and E. G. Soyak, "Low-Powered Agriculture IoT Systems with LoRa," 2020 IEEE Microwave Theory and Techniques in Wireless Communications (MTTW), 2020, pp. 178-183. https://doi.org/10.1109/MTTW51045.2020.9244927

[7] F. S. Mukti, P. D. P. Adi, D. A. Prasetya, V. Sihombing, N. Rahanra, K. Yuliawan, and J. Simatupang, "Integrating Cost-231 Multiwall Propagation and Adaptive Data Rate Method for Access Point Placement Recommendation" International Journal of Advanced Computer Science and Applications(IJACSA), vol. 12, no. 4, 2021. https://doi.org/10.14569/IJACSA.2021.0120494 
[8] F. U. Khan, A. N. Mian, and M. T. Mushtaq, "Experimental testbed evaluation of cell level indoor localization algorithm using Wi-Fi and LoRa protocols," Ad Hoc Networks, vol. 125, p. 102732, February 2022. https://doi.org/10.1016/j.adhoc.2021.102732

[9] F. Zhang, Z. Chang, J. Xiong, and D. Zhang, "Exploring LoRa for Sensing," GetMobile: Mobile Computing and Communications, vol. 25, no. 2, June 2021, pp 33-37. https://doi.org/10.1145/3486880.3486890

[10] H. Kasral, M. Taufik, R. H. Y. Perdana, A. E. Rakhmania, "Digital centralized water meter using 433 MHz LoRa", Bulletin of Electrical Engineering and Informatics, vol. 10, no. 4, pp. 2062-2071, August 2021. https://doi.org/10.11591/eei.v10i4.2950

[11] J. Wang, Y. Liu, Z. Lei, K. Wu, X. Zhao, C. Feng, H. Liu, X. Shuai, Z. Tang, L. Wu, S. Long, and J. Wu, "Smart Water Lora IoT System," ICCET '18: Proceedings of the 2018 International Conference on Communication Engineering and Technology, February 2018, pp 48-51. https://doi.org/10.1145/3194244.3194260

[12] J. Gresl, S. Fazackerley, and R. Lawrence, "Practical Precision Agriculture with LoRa based Wireless Sensor Networks," Proceedings of the 10th International Conference on Sensor Networks, 2021. https://doi.org/10.5220/0010394401310140

[13] L. -T. Tu, A. Bradai, Y. Pousset, and A. I. Aravanis, "Energy Efficiency Analysis of LoRa Networks," IEEE Wireless Communications Letters, vol. 10, no. 9, pp. 1881-1885, Sept. 2021. https://doi.org/10.1109/LWC.2021.3084996

[14] M. El-Aasser, P. Edward, M. Mandour, M. Ashour, and T. Elshabrawy, "A comprehensive hybrid bit-level and packet-level LoRa-LPWAN simulation model," Internet of Things, vol. 14, 2021. https://doi.org/10.1016/j.iot.2021.100386

[15] M. S. A. Muthanna, A. Muthanna, A. Rafiq, M. Hammoudeh, R. Alkanhel, S. Lynch, and A. A. A. El-Latif, "Deep reinforcement learning based transmission policy enforcement and multi-hop routing in QoS aware LoRa IoT networks," Computer Communications, vol. 183, pp. 33-50, 2022. https://doi.org/10.1016/j.comcom.2021.11.010

[16] R. M. Kingsta, A. S. Saumi and P. Saranya, "Design and Construction of Arduino Based pH Control System for Household Waste Water Reuse," 2019 3rd International Conference on Trends in Electronics and Informatics (ICOEI), 2019, pp. 1037-1041. https://doi.org/10.1109/ICOEI.2019.8862752

[17] N. Hashim, F. Idris, T. N. A. Tuan Ab Aziz, S. H. Johari, R. Mohd Nor, and N. Ab Wahab "Location tracking using LoRa," International Journal of Electrical and Computer Engineering, vol. 11, no. 4, August 2021. http://doi.org/10.11591/ijece.v11i4.pp3123-3128

[18] P. Branch, "Propagation Measurements and Models of 915 MHz LoRa Radio in a Block Cave Gold Mine," 2021 International Conference on Information Networking (ICOIN), January 2021. https://doi.org/10.1109/ICOIN50884.2021.9333935

[19] P. D. P. Adi and A. Kitagawa, "A performance of radio frequency and signal strength of LoRa with BME280 sensor," TELKOMNIKA Indonesian Journal of Electrical Engineering, vol. 18, no. 2, pp. 649-660, April 2020. https://doi.org/10.12928/telkomnika.v18i2.14843

[20] P. D. P. Adi and A. Kitagawa, "Performance Evaluation of LoRa ES920LR $920 \mathrm{MHz}$ on the Development Board," International Journal of Advanced Computer Science and Applications, vol. 11, no. 6, January 2020. https://doi.org/10.14569/IJACSA.2020.0110602

[21] P. D. P. Adi and A. Kitagawa, "A Review of the Blockly Programming on M5Stack Board and MQTT Based for Programming Education," 2019 IEEE 11th International Conference on Engineering Education (ICEED), 2019, pp. 102-107. https://doi.org/10.1109/ICEED47294.2019.8994922

[22] P. D. P. Adi, A. Kitagawa, and J. Akita, "Finger Robotic control use M5Stack board and MQTT Protocol based," 2020 7th International Conference on Information Technology, Computer, and Electrical Engineering (ICITACEE), pp.1-6, 2020. https://doi.org/10.1109/ICITACEE50144.2020.9239170

[23] P. D. P. Adi and R. Arifuddin, "Design of Tsunami Detector based Sort Message Service using arduino and sim900a to GSM/GPRS module," jeemecs (Journal of Electrical Engineering Mechatronic and Computer Science), vol. 1, no. 1, July 2018. https://doi.org/10.26905/jeemecs.v1i1.1982

[24] R. Hamdi, E. Baccour, A. Erbad, M. Qaraqe, and M. Hamdi "LoRa-RL: Deep Reinforcement Learning for Resource Management in Hybrid Energy LoRa Wireless Networks," IEEE Internet of Things Journal, September 2021. https://doi.org/10.1109/JIOT.2021.3110996

[25] S. Mondal, S. Karuppuswami and P. Chahal, "ID Integrated Batteryless Wireless Digital pH Sensor," in IEEE Sensors Journal, vol. 19, no. 24, pp. 12079-12086, Dec.15, 2019. https://doi.org/10.1109/JSEN.2019.2939926

[26] T. Karunathilake, A. Udugama, and A. Förster, "LoRa-DuCy: Duty Cycling for LoRa-Enabled Internet of Things Devices," 2021 Twelfth International Conference on Ubiquitous and Future Networks (ICUFN), August 2021. https://doi.org/10.1109/ICUFN49451.2021.9528805

[27] T. Osmëni and M. Ali, "LoRa IoT WSN for E-Agriculture," $4^{\text {th }}$ International Conference on Emerging Technologies in Computing 2021 (iCETiC21) UK, August 2021. https://doi.org/10.1007/978-3-030-90016-8_6

[28] V. M. Fialho, "Integer N Synthesizer Design for LoRa Transceivers," International Journal of Innovative Technology and Exploring Engineering, vol. 10, no. 10, pp. 101-106, August 2021. https://doi.org/10.35940/ijitee.J9447.08101021

[29] W. Xiao, N. E. Rachkidy, and A. Guitton, "Recovering Colliding LoRa Frames from Uncertainties Using LoRa Coding," IEEE 46 $6^{\text {th }}$ Conference on Local Computer Networks (LCN), October 2021. https://doi.org/10.1109/LCN52139.2021.9524949 
[30] Y. Ye, Y. Yang, L. Zhu, J. Wang, and D. Rao, "A LoRa-based Low-power Smart Water Metering System," 2021 IEEE International Conference on Consumer Electronics and Computer Engineering (ICCECE), pp. 301-305, 2021. https://doi.org/10.1109/ICCECE51280.2021.9342327

\section{BIOGRAPHY OF AUTHORS}

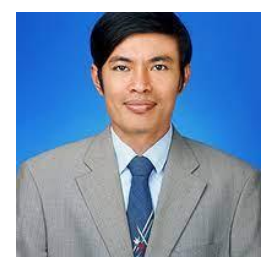

Puput Dani Prasetyo Adi is Lecturer at the Department of Electrical Engineering, University of Merdeka Malang, received a Doctor Engineering (Dr. Eng) from Kanazawa University Japan in 2020 September; he also joined with Micro Electrical Research Laboratory with Professor Akio Kitagawa, he focuses on the researcher in Wireless Sensor Network, Internet of Things and LPWAN. Email: puput.danny@unmer.ac.id

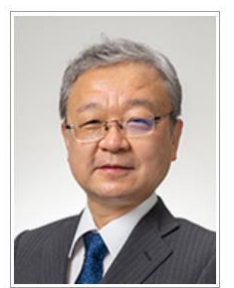

Akio Kitagawa is from the Faculty of Electrical, Information and Communication Engineering, Kanazawa University, Institute of Science and Engineering. He is a Professor from Kanazawa University. The bachelor's degree is from College and School Educational Field, Division of Electrical Engineering and Computer Science, Graduate School of Natural Science and Technology. His master's degree from the Division of Electrical Engineering and Computer Science, Graduate School of Natural Science and Technology. His doctoral degree is from Course in Information and Communication Engineering, School of Electrical, Information and Communication Engineering, College of Science and Engineering. Email: kitagawa@merl.jp

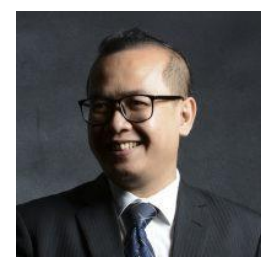

Dwi Arman Prasetya is a Lecturer at the Department of Electrical Engineering, University of Merdeka Malang. He receives a Doctor Engineering (Dr. Eng) from Tokushima University Japan. He is also Vice-Chancellor at the University of Merdeka Malang. He focuses on research in Robotics. Email: arman.prasetya@unmer.ac.id

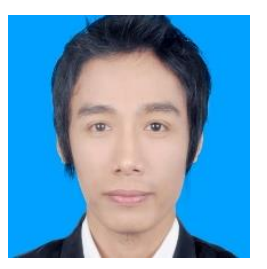

Rahman Arifuddin is a Lecturer at the Department of Electrical Engineering, University of Merdeka Malang. Currently, he is studying Doctoral at Tokushima University Japan (2021-2024). He is also head of the study program at the Department of Electrical Engineering, University of Merdeka Malang. He focuses on the researcher in sensors and agriculture research. Email: rahman.arifuddin@unmer.ac.id

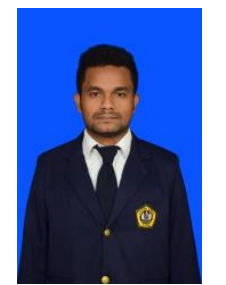

Stanislaus Yoseph is a Bachelor's Degree from the Department of Electrical Engineering, University of Merdeka Malang. Currently, he is a lecturer assistant at the Department of Electrical Engineering, University of Merdeka Malang; he focuses on a research in Robotics, sensors, and agriculture research. Email: Stanislaus.yoseph@gmail.com 